\title{
CONTRACEPTIVE USE \\ IN HUNGARY: \\ PAST TRENDS AND \\ ACTUAL BEHAVIOUR
}

\section{Zsuzsanna Makay}

\section{ABSTRACT}

In the present study I look first at findings of earlier surveys on women's birth control behavior since 1958 in Hungary. I then turn to the detailed analysis of the birth control practices of Hungarian women based on data from the Generations and Gender Survey (2008-2009). First I examine the influences on whether partnered women of reproductive age employ any birth control methods or not, and then I explore the methods that are chosen. What emerges from this examination is that modern contraception has spread widely in Hungary since the 1960s, but in 2009 a quarter of Hungarian women were still not using any method of birth control, or else they were merely using a traditional low-efficiency types. The profile of such abstainers is clear: they are reaching the end of their reproductive period, have a low level of education, are married, have financial difficulties, are generally childless, and do not plan to have a child in the short-term. The results of a multinomial logistic model show that there are also several demographic and social factors behind choosing a method of contraception. In 2009 the most common of these was the condom, followed by birth control pills ("the Pill") and intra-uterine devices (IUDs, "the coil"). Finally, the study compares birth control in five European countries and its changes since the 1990s. The use of the Pill declined in all the countries in the 1990s, and only in Bulgaria and Hungary have condom users outnumbered pill-takers.

Keywords: contraception, birth control, Hungary, Europe, Generations and Gender Survey 
Zsuzsanna Makay

Hungarian Demographic Research Institute

E-mail: makay@demografia.hu

\section{INTRODUCTION}

Regular inquiries into family planning and the use of contraception in Hungary, known as Fertility, family planning surveys, were taken three times between 1958 and 1974 . Women of reproductive age were asked about their family planning and use of contraceptives. At that time scholars were primarily interested in the extent to which newlywed couples used intentional family planning: Were young people planning the number of children they wanted to have? Did they reflect on the size of their future family? Scholars also wanted to know what the main methods of birth control were, if any (Klinger, 1975).

After the collapse of socialism at the end of the 1980s, new data became available thanks to the international Family and fertility survey, conducted in Hungary from 1992-1993. Since that time, however, very few studies have treated the issue, and no comprehensive survey has centered on reproductive and sexual behavior, family planning or contraception in Hungary. Still, the subject has major social and health implications. Modern contraceptive methods provide almost total protection from conception: their use is crucial in conscious family planning, preventing unwanted pregnancy, and reducing the incidence of abortion.

There are several other important factors to consider. The average age of childbearing is rising. The mean age at first birth was 28.3 in 2014, although it was only 23 years twenty years earlier (KSH, 2015). Nowadays first birth is preceded by a lengthy period of about a decade, in which men and women have sexual relations while avoiding pregnancy. Among young people birth control has a major role in postponing birth of the first child. Knowledge of the potentials of birth control and the methods actually used in that period have an importance that extends beyond family planning such as avoiding abortion, and including the quality of young people's sexual lives and relationships. Birth control methods allow the timing of the first birth and the spacing of subsequent children to be matters of conscious decision-making.' After the desired number of children have been born, it is possible to avoid further pregnancies and limit the ultimate number of offspring. Because of this, family planning continues to

${ }^{1}$ Provided, of course, there is no medical problem that impedes pregnancy. 
be a factor in peoples' lives through most of their reproductive years, and it only ceases when the couple decides to bear a child.

This study seeks to examine the family-planning practices of partnered women, based on survey data from 2009. It applies socio-demographic background variables to identify factors behind contraception use and the choice of the primary method. This knowledge helps us understand the familyplanning practices of women and single out the possibilities to further reduce the number of abortions.

The next section of the paper looks briefly at the appearance and the spread of modern family-planning methods in European countries. Turning to Hungary, the following part presents the family-planning practices in the second half of the 20th century up to 1993 through earlier findings. Then I describe the survey and the sample of the 2009 data, followed by the descriptive and multivariate findings regarding who controls unwanted pregnancy and who does not, including which methods are most commonly used. What emerges from this examination is that surprising changes occurred between 1993 and 2009 in the relative popularity of methods. This result requires separate explanation. The final empirical section analyzes the same changes on a European level in four other countries: how family-planning methods have changed over the last decade and a half, and which countries Hungary most resembles in this respect. In the conclusion, attention is drawn to the most revealing relationships and suggestions for further research.

\section{THE SOCIAL ROLE AND THE SPREAD OF CONTRACEPTION IN EUROPE}

Defined as those providing full protection against conception if used correctly, modern methods of family planning appeared in developed countries in the mid20th century, ${ }^{2}$ although contraception practices had existed before then. There have been reasons to avoid unwanted pregnancy since ancient times: avoiding the disgrace of bearing an illegitimate child, securing income from prostitution, or in the case of married women, limiting the number of children for reasons of health or personal appearance (van de Walle, 2005). Apart from many folk remedies (carrying a vial of some substance, coughing or jumping about after intercourse, etc.), the most common methods were abstinence or interruption

\footnotetext{
${ }^{2}$ Such "modern" methods are sterilization (surgical intervention), condoms, various intra-uterine devices (coil), and various types of hormonal treatment (tablets, injection, implant) (Frejka, 2008).
} 
of coitus before ejaculation, although the latter leads to pregnancy in a quarter of cases (Moreau, 2011; Paládi-Kovács, 1988-2011). The methods used up to the end of the 19th century were far from reliable. For a long time it was thought, for instance, that women were most fertile in the days right after menstruation, and there pregnancy could be avoided by abstinence in that period. It was believed that a period of sterility ensued, when the chance of conception was minimal (van de Walle, 2005). In fact the opposite was the case and such tactics actually maximized the chance of conception.

Apart from such imperfect methods, the other earlier means of birth control was induced abortion. Prevalent religious norms in most countries meant such intervention was illegal. Although there are no data available, it can be assumed that there were a large number of midwives or quacks prepared to administer substances (poisons) by mouth or by insertion into the womb, or in worse cases, to physically remove the fetus. Such intervention often had serious complications that could cost the woman her life.

In spite of the unreliability of earlier contraception methods, they were effective enough cumulatively to cause an appreciable decline in fertility in developed countries. Certain members of the population succeeded, indeed, in considerably limiting their fertility by ineffective traditional methods, periodic sexual abstention, and non-medical abortion. Over a few decades around the turn of the 19th and 20th centuries, the total fertility rate in Europe fell from about 4.5 to 2.5-3.0 (Monnier, 2006), although the gain in reliability began only close to the end of that period.

Only in the 20th century, however, did the innovations allow reliable and deliberate planning and spacing of births. By mid-century, medical science had reached a standard whereby the physiological process of conception and methods of preventing it were understood sufficiently, and technical developments were at a stage where devices of requisite reliability and price were generally available. It became possible to produce synthetic hormones, which allowed the tablet form of contraception ("the Pill") to advance. (Previously, animal hormones had been used in making the Pill.) The production of modern condoms was enabled by the development of liquid latex. Flexible plastic, then a novelty, led to long-life intra-uterine contraceptive devices (such as the coil) that could be inserted for as many as ten years (Quarini, 2005).

The new methods faced religious and ethical resistance in mostly Catholic countries. The church condoned only natural methods such as periodical abstinence in family planning; termination of pregnancy and contraceptive devices were banned in most European countries. Finally, in the 1960s, most 
Western countries began to lift their bans on contraception methods and permit abortion under certain conditions (Cahen, 2007).

There is a major difference in the regulatory courses taken in East and in West European countries. The former legalized abortion even before modern contraception methods had spread, primarily in the 1950s, making this the primary method of birth control. Western countries looked instead to wider use of contraceptives, and did not liberalize their abortion regulations until some years later. Because of this, abortion remained a secondary form of birth control, used most often when contraception had failed for some reason (Blayo, 1991; Monnier, 2006).

\section{HUNGARY'S BIRTH CONTROL PRACTICE BEFORE AND AFTER THE CHANGE OF SYSTEM IN 1989}

Hungary liberalized induced abortion in 1956. A few years later, there was one termination occurring for every live birth (Figure 1). A record number of terminations ensued in the mid-1960s: 140 induced abortions per 100 live births. We will show that almost $70 \%$ of women practicing birth control were using a natural method, mainly coitus interruptus, also known as the withdrawal method, as well as periodic abstinence, and that there was no ethical barrier to abortion, which was socially accepted at that time.

Figure 1: Number of induced abortions for 100 live births in Hungary, 1950-2015

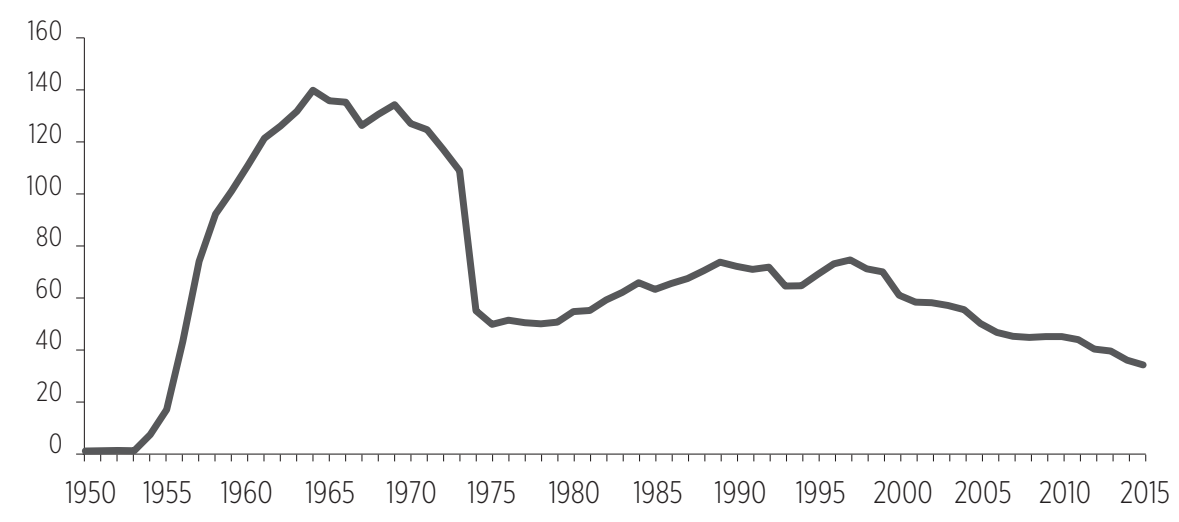

Source: Database of the Hungarian Central Statistical Office. 
The first oral contraceptive made in Hungary was a pill with a high hormone content named Infecundin, introduced in 1967 (Acsádi et al., 1970). The regulations at the time did not make it easy to obtain it, as it could only be prescribed by a specialist, but the initial controls were relaxed in stages and tablet variants with lower hormone content became available. The number of users increased steadily. The 1973 order on demographic policy allowed almost all doctors to prescribe this pill free under health insurance (Surányi, 1975). The same order that made contraceptives more readily available restricted the possibility of induced abortion. The combined effect was that the use of modern contraception methods rose by $71 \%$ in the first three quarters of 1974 and that of induced abortions fell by 40\% (Vukovich, 1991). Still, the Pill was not uniformly welcomed by women, mainly due to fear of its side effects (Klinger, 1975).

Another modern method appeared at the beginning of the 1970s: the intrauterine device (IUD) or coil. This could be fitted only at an inpatient facility, so that strong geographical inequalities developed, as not all regions had one (Surányi, 1975).

Comparison of data shows well how the use of contraceptive methods changed between 1958 and 1993. First, the proportion of those of childbearing age protecting themselves from unwanted pregnancy rose from 58\% to 94\% (Table 1). Second, there was a large shift in the primary methods used. In 1958 half of women used the withdrawal method; by 1993 there were only 9\% doing so. The importance of the Pill and the coil rose; by 1993 more than half of women took the Pill and a quarter used the IUD. The use of the male condom fluctuated; 21\% used it in 1958 - a high proportion (which may be overestimated), compared to the novelty of this method at the time -, and only 9\% in 1974 and 11\% in 1993 did so. So the so-called "contraceptive revolution", with modern methods replacing traditional ones, took little more than three decades in Hungary (Frejka, 2008). Indeed in the first stage, in 1966-1974, the proportion of women using traditional methods (mainly coitus interruptus and periodical abstinence) fell from $70 \%$ to $43 \%$, and over a third of the women were taking the hitherto unknown Pill. This became yet more marked by the early 1990s, with half of women taking the Pill. Between 1974 and 1993 the use of oral contraception had reached the European level, in an era when Hungary's abortion incidence was still very high: over 70 terminations per 100 live births early in the 1990s. 
Table 1: Change in the contraception practices of women between 1958 and 1993 (\%)

\begin{tabular}{|c|c|c|c|c|}
\hline & \multicolumn{3}{|c|}{$\begin{array}{l}\text { Married women aged } \\
\text { under } 35\end{array}$} & \multirow{2}{*}{$\begin{array}{c}\text { Women aged } 18-41 \text { in } \\
\text { cohabiting partnershipa } \\
\text { 1992-1993 }\end{array}$} \\
\hline & 1958 & 1966 & 1974 & \\
\hline \multicolumn{5}{|c|}{ The use of birth control } \\
\hline Employing some form of birth control & 58.0 & 68.0 & 75.0 & 93.9 \\
\hline Not employing any form of birth control & 42.0 & 32.0 & 25.0 & 6.1 \\
\hline Total & 100.0 & 100.0 & 100.0 & 100.0 \\
\hline \multicolumn{5}{|c|}{ Distribution of methods } \\
\hline Coitus interruptus & 52.0 & 62.0 & 35.0 & 8.7 \\
\hline Periodical abstinence and other natural methods & 15.0 & 8.0 & 8.0 & 4.3 \\
\hline Condom & 21.0 & 17.0 & 9.0 & 10.7 \\
\hline Pessary & 5.0 & 6.0 & 2.0 & - \\
\hline IUD & - & - & 7.0 & 24.0 \\
\hline Oral (pill) & - & 0.0 & 36.0 & 52.0 \\
\hline Other or unknown & 7.0 & 7.0 & 3.0 & 0.3 \\
\hline Total & 100.0 & 100.0 & 100.0 & 100.0 \\
\hline Number of cases & 4797 & 4370 & 3283 & 2001 \\
\hline
\end{tabular}

Source: Klinger, 1975, p.234 and 244; United Nations Economic Commission for Europe, 1999.

Notes: The table shows the main methods of contraception employed at the time of the surveys. Surveys: 1958 and 1966: Fertility and Family Planning Survey; 1974: Fertility and Family Planning Survey, general (household) part; 1992-1993: Family and Fertility Survey.

a We do not know if respondents intended to become pregnant and raise a child at the time of the survey.

Sterilization, either of women or men, is a very uncommon and rare method of birth control in Hungary. Less than $1 \%$ of women were sterilized for contraceptive reasons in 1993, and even less before that (Klinger, 1975). This method of birth control has not spread since the 1990s, although legislation makes it possible for both sexes to ask for sterilization as a form of contraception (even if there have been several changes in the last decades concerning the age at which this may be asked and the number of children being born at the moment of the demand).

We now turn to the most recent data of 2009 in order to review the latest developments in contraceptive use in Hungary. 


\section{BIRTH CONTROL PRACTICES IN HUNGARY IN 2009}

\section{Data and sample}

The study uses data from the survey Turning Points of the Life Course (the Hungarian Generations and Gender Survey), conducted by the Hungarian Demographic Research Institute. This longitudinal survey began in 2001 with the participation of 16,000 men and women aged 18-75. Four waves had taken place by 2013. Here I analyze data from the third wave, taken at the turn of 2008-2009 with the original respondents and 1000 additional respondents aged 20-25.

The questionnaire of the third wave includes a section that asks about family planning and contraceptive practices. Unlike the rest of the questionnaire, the questions were not asked by the interviewer, but were self-administered by the respondents and attached to the questionnaire in a sealed envelope. It seemed wise to trust the responses in this part to the respondent alone, in view of the sensitive nature of the topic. This presumably increased the willingness to respond and the reliability of the data.

The response sheet had two pages and was divided according to whether or not the respondents (or their partners) were expecting a child at the time of the survey. The questions about birth control were presented to those who (themselves or their partners) were not pregnant at the time of the survey and were not trying to conceive. The first question to this group was "Are you or your partner using or doing anything to prevent pregnancy?" (yes/no). The next question was, "If yes, mark the method or methods you use". They could choose one or more of the ten methods listed ${ }^{3}$.

The special feature of the survey was that the questions on birth control could be analyzed in conjunction with the respondents' answers in the traditional questionnaire, where there was information, for example, on age, partnership status, educational attainment, and living standard, so that profiles could be compiled of those who did and did not employ birth control and what factors affected their choice of method. The self-administered questions were not seen or checked in any way by the interviewer, yet they were filled in with exemplary precision - the decisive majority of respondents answered all applicable questions consistently.

\footnotetext{
${ }^{3}$ The proposed answers were: 1) condom, 2) pill, 3) IUD, 4) diaphragm/ cervical cap, 5) foam/cream/ jelly/suppository, 6) injectables, 7) implants, 8) emergency contraception afterwards, 9) withdrawal, 10) safe period method (rhythm). There was no possibility to say that sterilization prevents pregnancy.
} 
Below we analyze the responses of all women of reproductive age (aged 20-49). The sub-sample includes those who were probably the most affected by birth control issues, i.e. women who had a partner (either cohabiting or not), who were not pregnant and who were not trying to conceive at the time of the interview.

So the data are drawn from the responses of 1824 women. The questionnaire contains no questions on sexual life. We have to assume that partnered women had sexual relations and therefore had to face the question of becoming pregnant or not.

\section{Factors behind the choice of certain contraception methods}

First I analyzed the distribution of women by the use of birth control. Asked whether or not they practiced birth control: $87.6 \%$ of women said yes and $12.4 \%$ answered no (Table 2), i.e. every tenth woman in Hungary failed to practice birth control in 2009 despite living in a stable partnership and not planning to become pregnant. The uptake was higher in 1993, when $93.9 \%$ of women stated that they employed some birth control method (see Table 1). The difference between the two tables, however, needs to be considered; the earlier one took a younger sample: women cohabiting with their partner and under the age of 42 . In the second table the age limit was 49 and those in a living-apart-together (LAT) relationship were also included. If the 2009 figures are adjusted to the criteria of the 1993 sample, 91\% were using some birth control method; the proportion had barely changed over one decade and a half.

Table 2: The distribution of women by the use of birth control in 2008-2009 in Hungary

\begin{tabular}{lcc} 
& $\%$ & Number of cases \\
\hline Do not use birth control & 12.4 & 216 \\
Use birth control & 87.6 & 1608 \\
Total & 100.0 & 1824 \\
\hline
\end{tabular}

Sources: Hungarian Generations and Gender Survey, Wave 3, 2008-2009 (HDRI). Sample: partnered women aged 20-49 who are not pregnant and not trying to conceive.

Further differences between non-users and users also need to be considered, such as social and demographic background, partnership status, age, educational attainment, and living standards. 
An age breakdown shows that the younger the respondents, the fewer fail to practice birth control; fewer than 5\% of 20-24 year olds are non-users (Figure 2). The non-user proportion rises with age, with over a quarter of 45-49 year olds failing to protect against unwanted pregnancy. Some of the latter cohort is presumably undergoing menopause, which could justify abandoning birth control, although the figures clearly show that the proportion of non-users is somewhat above average even among the next cohort down, the 40-45 year olds.

Figure 2: The use of birth control by age group (\%), in 2008-2009 in Hungary

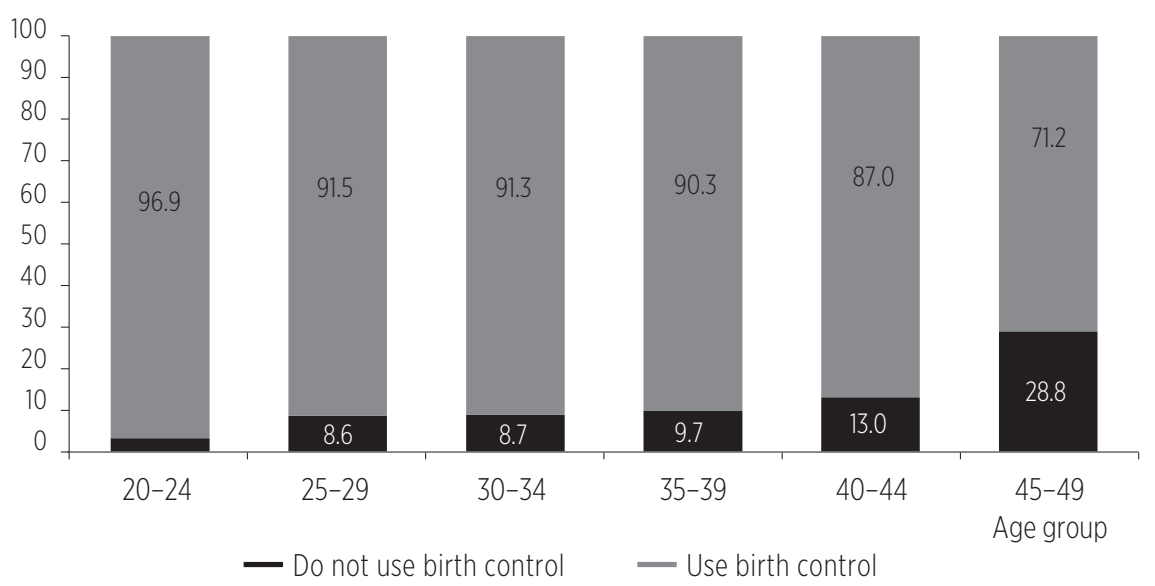

Source: Hungarian Generations and Gender Survey, Wave 3, 2008-2009 (HDRI).

Sample: partnered women aged 20-49 who are not pregnant and not trying to conceive.

Number of cases: 1824.

In terms of partnership status, the more secure the relationship, the lower the proportion of users (Figure 3). Over four-fifths of married women protect against unwanted pregnancy, but the proportion is far higher (93\%) in LAT relationships. Since marriage can be considered a more stable status (legally at least), these couples may worry less concerning unwanted pregnancy than those not married to their partners or not cohabiting with them. In those cases, women seem to take more care to avoid pregnancy. Of course other factors also apply, such as age. Because of this, a multivariate model is needed to check the effects of individual factors on birth control use. 
Figure 3: The use of birth control by partnership status (\%) in 2008-2009 in Hungary

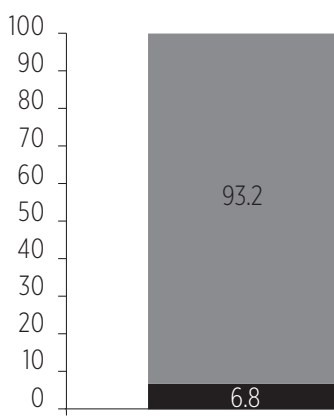

Living apart together

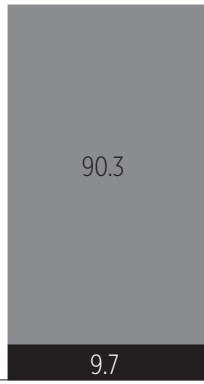

Cohabitation

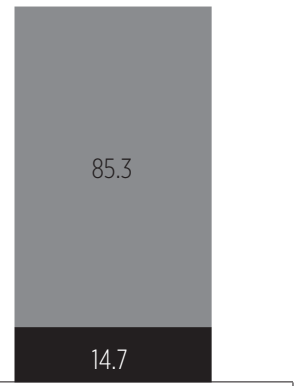

Marriage

- Do not use birth control _ Use birth control

Source: Hungarian Generations and Gender Survey, Wave 3, 2008-2009 (HDRI).

Sample: partnered women aged 20-49 who are not pregnant and not trying to conceive.

Number of cases: 1824.

Analysis by education shows that the higher the education attainment is, the more common it is to protect against unwanted pregnancy (Figure 4). Of women with up to eight grades of schooling, almost a quarter is non-users, while among university graduates it is just over $7 \%$. Those with college degree resemble most closely those with general secondary education: the proportion of users is around $90 \%$ in both groups.

Figure 4: The use of birth control by educational attainment (\%) in 2008-2009 in Hungary

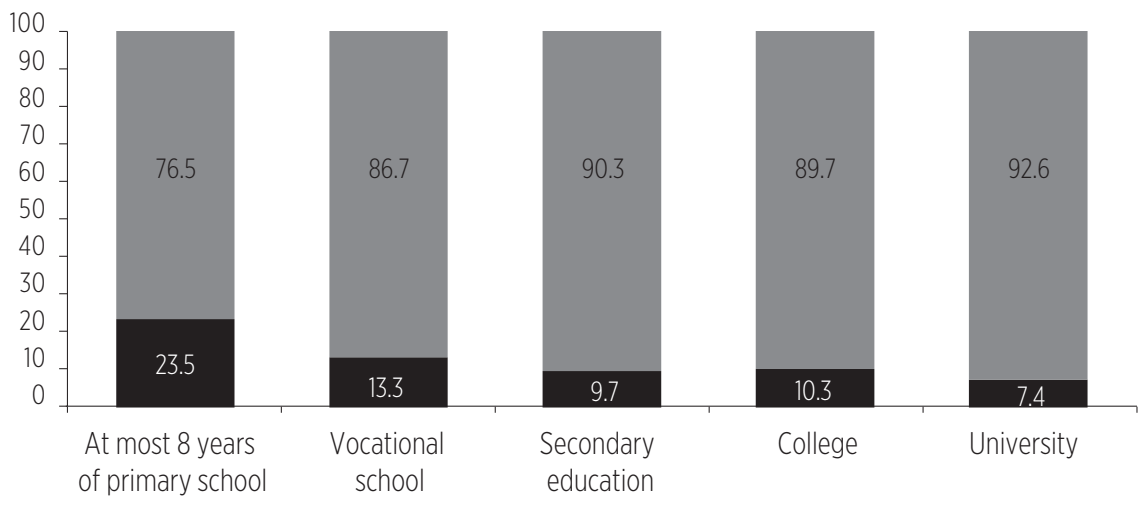

- Do not use birth control _ Use birth control 
The survey contained several questions on respondents' income and living standards. Here a "subjective" variable was analyzed, which does not specify the income as an absolute value, but rather expresses the scope of the income and degree of satisfaction with it. There were five categories of answers: 1) have to go without, 2) financial problems from month to month, 3) can just make ends meet by budgeting carefully, 4) live acceptably, and 5) live without financial problems. The first two and the last two categories were combined, resulting in three categories: i) living in hardship, ii) living adequately, and iii) living well. Comparing the responses with contraception habits, it was clear that the higher the living standard, the higher the proportion of birth control users (Figure 5). Of those living in hardship, 18\% were non-users, as were 12\% of those living adequately, and $10 \%$ of those living well.

Figure 5: The use of birth control by subjective living conditions (\%) in 2008-2009 in Hungary

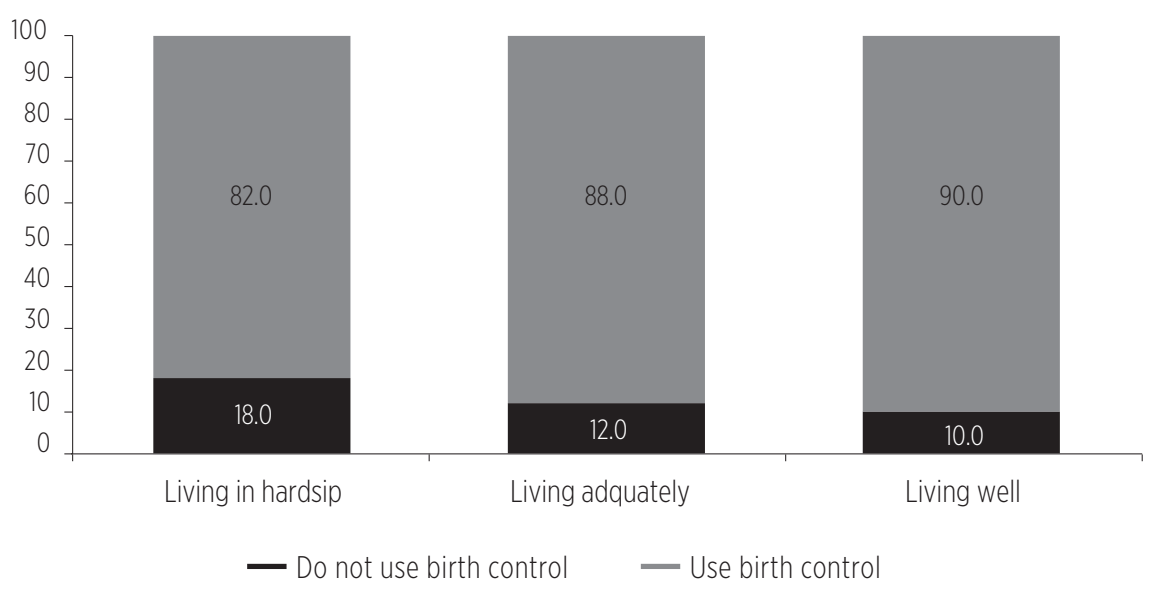

Source: Hungarian Generations and Gender Survey, Wave 3, 2008-2009 (HDRI).

Sample: partnered women aged 20-49 who are not pregnant and not trying to conceive. Number of cases: 1824.

The descriptive findings suggest that the presented socio-demographic factors are linked to the willingness or unwillingness of respondents to protect against unwanted pregnancy. The next section examines whether these relationships hold in a multivariate model. 


\section{Multivariate analysis of the use or non-use of contraception}

Here we apply a logistic regression analysis to estimate the probability of using contraception. The variables covered in the descriptive section appear in the model as explanatory variables: age group, partnership status, educational attainment, and subjective living conditions. The question remains whether these factors still affect the use of contraception, while controlling for other variables. We also considered whether or not two further variables might play a part: the number of children, and whether respondents want to have children within three years.

Regarding the number of children, it is assumed that childless couples are more likely to practice some form of birth control than parents. The birth of a first child is typically planned more carefully, as the change entailed is greater than with the addition of a second or third child. The question of whether or not they "want to have a child during the next three years" illuminates future childbearing plans. If they do not want children within three years and clearly have no plans to have any in the near future, it is assumed that they are more likely to be using birth control. Conversely, the use of birth control can be less frequent if the couple will find it acceptable for planned children to be born earlier than envisaged.

The findings from the multivariate model confirm the earlier conclusions about age, partnership status, educational attainment and subjective living conditions (Table 3). The 20-24 year-olds are significantly more likely and women aged over 34 are less likely than the 30-34 year-olds to use birth control. The regression model fails to confirm the descriptive finding that women in a LAT partnership are more likely to use a birth control method than cohabiting or married women. Married couples, however, are less likely to be users than unmarried ones. Educational attainment is a significant factor among the least and the most educated; fewer of the former use birth control than those with secondary education and women with tertiary education are more likely to use it. As the descriptive findings have shown, the use of birth control depends also on living conditions; those in situations of hardship are less likely to be users than those with an adequate living standard. The number of children shows a significant influence only among the childless: they are less likely to use birth control than parents, irrespective of other variables. This somewhat surprising result suggests that the childless are least concerned with the prospect of unwanted pregnancy. However, it also gains support from other sources that more than a third of the women undergoing an abortion in 2011 were childless (KSH, 2012). 
The use of birth control is strongly influenced by a desire to give birth in the near future. Those who say they would "definitely" or "probably" want to have a child within three years are significantly less likely to practice birth control. We cannot tell whether this is a matter of irresponsibility or those planning to have children later mind less if a child arrives earlier than expected.

Table 3: Probability of using or not using birth control (logistic regression model) in 2008-2009 in Hungary

\begin{tabular}{|c|c|c|c|c|}
\hline & & $\begin{array}{l}\text { Coefficient } \\
\text { (B) }\end{array}$ & $\begin{array}{l}\text { Signifi- } \\
\text { cance }(p)\end{array}$ & $\begin{array}{l}\text { Number of } \\
\text { cases }\end{array}$ \\
\hline \multirow{6}{*}{ Age group } & $20-24$ & 1.42 & $* * *$ & 224 \\
\hline & $25-29$ & - & n.s. & 261 \\
\hline & $30-34$ & 0 & ref. & 359 \\
\hline & $35-39$ & -0.55 & $*$ & 334 \\
\hline & $40-44$ & -0.99 & $* * *$ & 329 \\
\hline & $45-49$ & -1.97 & $* * *$ & 317 \\
\hline \multirow{3}{*}{ Partnership status } & LAT & - & n.s. & 281 \\
\hline & Cohabitation & 0 & ref. & 328 \\
\hline & Marriage & -0.46 & ${ }^{*}$ & 1215 \\
\hline \multirow{5}{*}{ Educational attainment } & $\begin{array}{l}\text { At most } 8 \text { years of } \\
\text { primary school }\end{array}$ & -0.88 & $* * *$ & 234 \\
\hline & Vocational school & - & n.s. & 354 \\
\hline & Secondary education & 0 & ref. & 756 \\
\hline & College degree & - & n.s. & 330 \\
\hline & University degree & 0.65 & ${ }^{*}$ & 150 \\
\hline \multirow{3}{*}{ Subjective living conditions } & Living in hardship & -0.52 & $* *$ & 311 \\
\hline & Living adequately & 0 & ref. & 844 \\
\hline & Living well & - & n.s. & 669 \\
\hline \multirow{4}{*}{ Number of children } & 0 & -1.27 & $* * *$ & 401 \\
\hline & 1 & - & n.s. & 382 \\
\hline & 2 & 0 & ref. & 702 \\
\hline & 3 or more & - & n.s. & 339 \\
\hline \multirow{4}{*}{$\begin{array}{l}\text { Want to have a child during } \\
\text { the next three years }\end{array}$} & Definitely yes & -1.26 & $* * *$ & 113 \\
\hline & Probably yes & -1.12 & $* * *$ & 203 \\
\hline & Probably no & 0 & ref. & 359 \\
\hline & Definitelyno & - & n.s. & 1149 \\
\hline
\end{tabular}

Source: Hungarian Generations and Gender Survey, Wave 3, 2008-2009 (HDRI).

Sample: partnered women aged 20-49 who are not pregnant and not trying to conceive.

Number of cases: 1824.

Notes: Other control variable: region in which the respondent completed the questionnaire. $\mathrm{n}$. s. = not significant; ref. $=$ reference category. Significance levels: ${ }^{*} p<0.01,{ }^{* *} p<0.05,{ }^{* * *} p<0.001$. 


\section{The most common methods of birth control}

This section analyzes what method of birth control is employed by those who protect against unwanted pregnancy. Those who use no birth control are not included in the analysis. Respondents could mark more than one of the ten methods of birth control listed in the questionnaire, but the number of respondents choosing more than one method was minimal, although using a combination of methods or various methods successively are not impossible. Still, the results show that users could easily name one method that they presumably used regularly.

The study refrains from describing each method in detail or analyzing its efficiency, as the latter in almost every case depends on the correct use of the method. The differences are more between those that offer 100\% safety if used correctly (the Pill and the coil) and those where the efficiency is very low even when used with care, such as coitus interruptus. There are cost differences among the methods as well, and some, such as the Pill and the coil require regular visits to the doctor. Hungary, incidentally, does not subsidize any method through social insurance, so price can be an important factor as well.

In 2009, the largest number of women practicing contraception were using condom. This was followed by the Pill, then coil (Table 4). So the order of popularity among the methods had changed completely since 1993; the proportion using the Pill had fallen by more than 20 percentage points, from $52 \%$ to $31 \%$. Condom (37\%) has taken over the Pill as the most popular method, although hardly more than 10\% were using it in 1993. In 1993 coil was more popular than condom, but in 2009 coil was only the third most popular method (18\%). In the same year,

Table 4: Birth control by contraception methods

$\begin{array}{lcc} & \% & \text { Number of women } \\ \text { Condom } & 36.8 & 584 \\ \text { Pill } & 30.5 & 489 \\ \text { Coil, IUD } & 18.0 & 300 \\ \text { Other hormonal methods } & 1.3 & 17 \\ \text { Natural methods } & 13.4 & 218 \\ \text { Total } & 100.0 & 1608\end{array}$

Source: Hungarian Generations and Gender Survey, Wave 3, 2008-2009 (HDRI).

Sample: partnered women aged 20-49 who are not pregnant, not trying to conceive and use birth control. Notes: Other hormonal methods include injection, implant, and emergency contraceptive pill (ECP). Natural methods are interrupted coitus, calendar method, local remedies, and vaginal pessary. 
$13 \%$ still used natural methods of protection - most commonly interrupted coitus (8\%), then the calendar method, also referred to as the rhythm method (2\%). The changes between 1993 and 2009 feature again later, but first it is time to look at what factors influence the choice of each method.

In the next section, respondents choosing other hormonal methods (only 1.3\%) are grouped together with those using a natural method in the "other methods" category, in which the decisive majority uses a natural method. In the descriptive analysis and then in the multivariate analysis, the aim is to know what factors affect the choice of contraception method.

\section{Factors behind the choice among the methods}

Contraception choice according by age group shows that methods diversify with increasing age (Figure 6). While $90 \%$ of $20-24$ s use condoms or the Pill (and only $10 \%$ use other methods), less than half of the $45-49$ s do so. This is explained primarily by fact that as age rises, women abandon the Pill and rely primarily on the coil and other (mostly natural) methods. $15 \%$ of women aged 30-34 use the coil; the proportion rises to a third for the 45-49s. Condom use varies and it is the most common method above the age of 30 .

Figure 6: Distribution of contraception methods by age group (\%) in 2008-2009 in Hungary

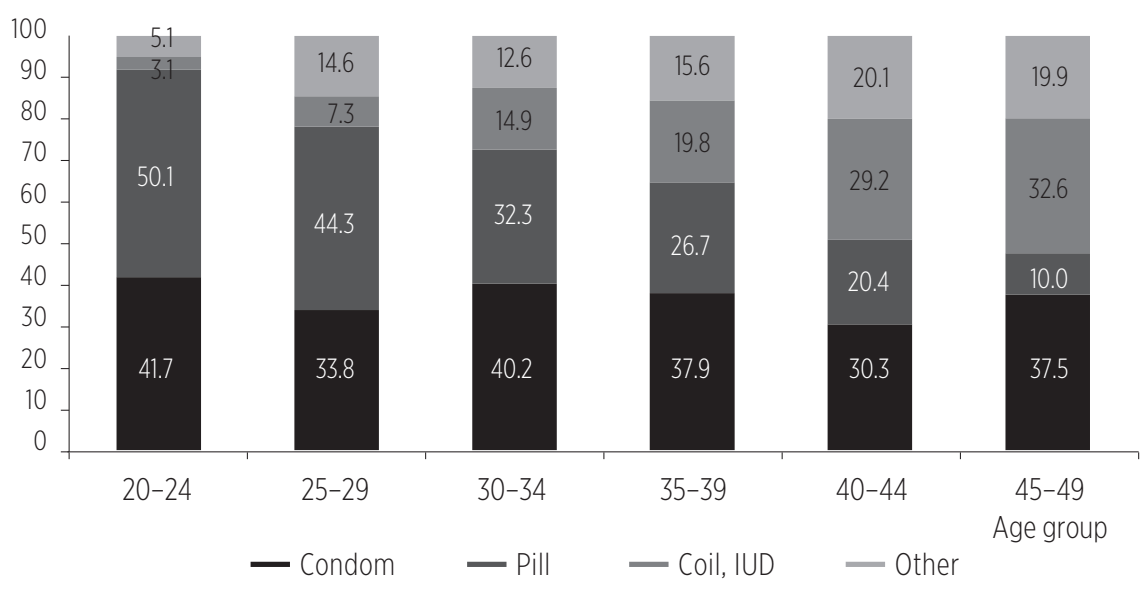

Source: Hungarian Generations and Gender Survey, Wave 3, 2008-2009 (HDRI).

Sample: partnered women aged 20-49 who are not pregnant, not trying to conceive and use birth control. Number of cases: 1608. 
Regarding partnership status, the proportion of condom users is remarkably stable; over a sixth of women protect from unwanted pregnancy this way (Figure 7). However, the Pill is more common in LAT relationships, while the coil and natural methods are used mostly by married couples. The intermediate category here consists of women in cohabiting relationships.

Figure 7: Distribution of contraception methods by partnership status (\%) in 2008-2009 in Hungary

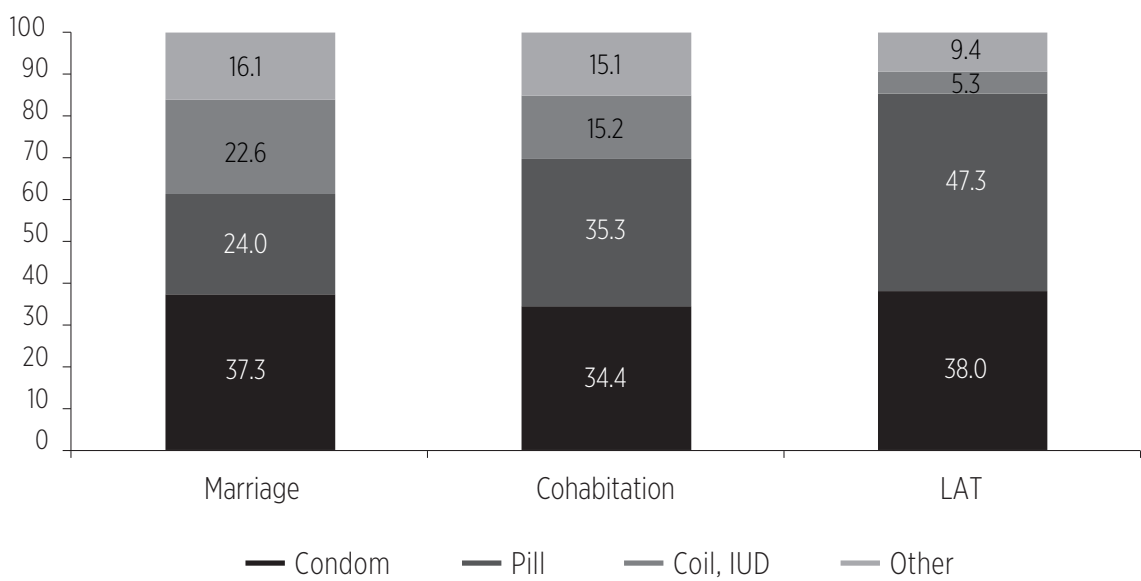

Source: Hungarian Generations and Gender Survey, Wave 3, 2008-2009 (HDRI).

Sample: partnered women aged 20-49 who are not pregnant, not trying to conceive and use birth control. Number of cases: 1608.

Regarding educational attainment, a far higher proportion of women use other, mainly natural methods in the lowest educational category (one in five women) than among university graduates (fewer than one in ten women) (Figure 8). 14-15\% of women with vocational, secondary or college education use other methods. Educational attainment seems to matter more in the case of condom use than the other factors: the proportion of condom user is much higher than the average (56\%) among university graduates, while it is less than a third among those with vocational education. Pill use is the same for the highest and lowest educational categories (under a quarter) but slightly higher for those with vocational or secondary schooling. The most common choice for those with vocational or primary education is the coil, which is used far more rarely by university graduates. 
Figure 8: Distribution of contraception methods by educational attainment (\%) in 2008-2009 in Hungary

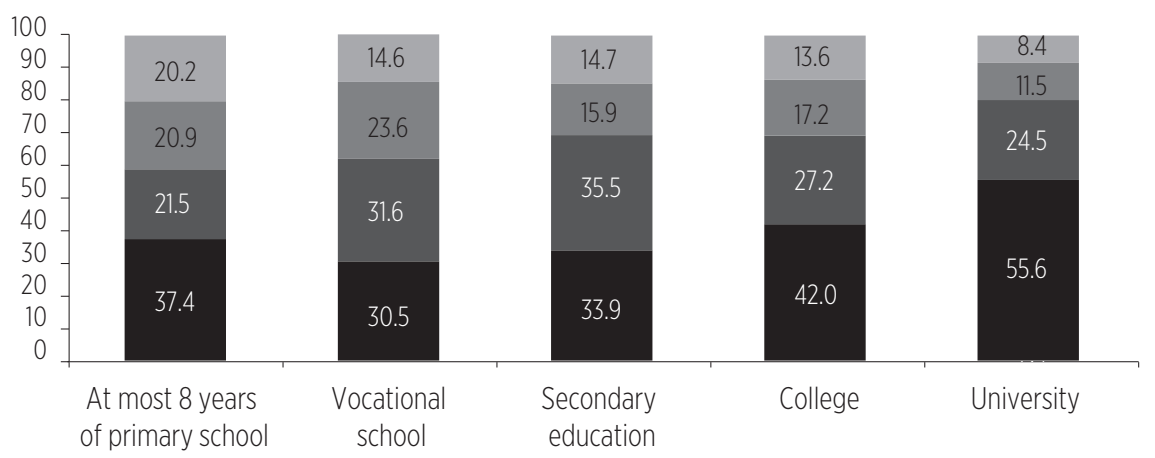

- Condom - Pill Coil, IUD $\quad$ - Other

Source: Hungarian Generations and Gender Survey, Wave 3, 2008-2009 (HDRI).

Sample: partnered women aged 20-49 who are not pregnant, not trying to conceive and use birth control. Number of cases: 1608.

As far as subjective living conditions is concerned, those with higher subjective income use condom and the Pill more often than those living in hardship, who tend to use coil or natural methods (Figure 9). Still, the methods used by the three groups are remarkably similar and multivariate analysis will offer further insights.

Figure 9: Distribution of birth control methods by method and subjective living conditions (\%) in 2008-2009 in Hungary

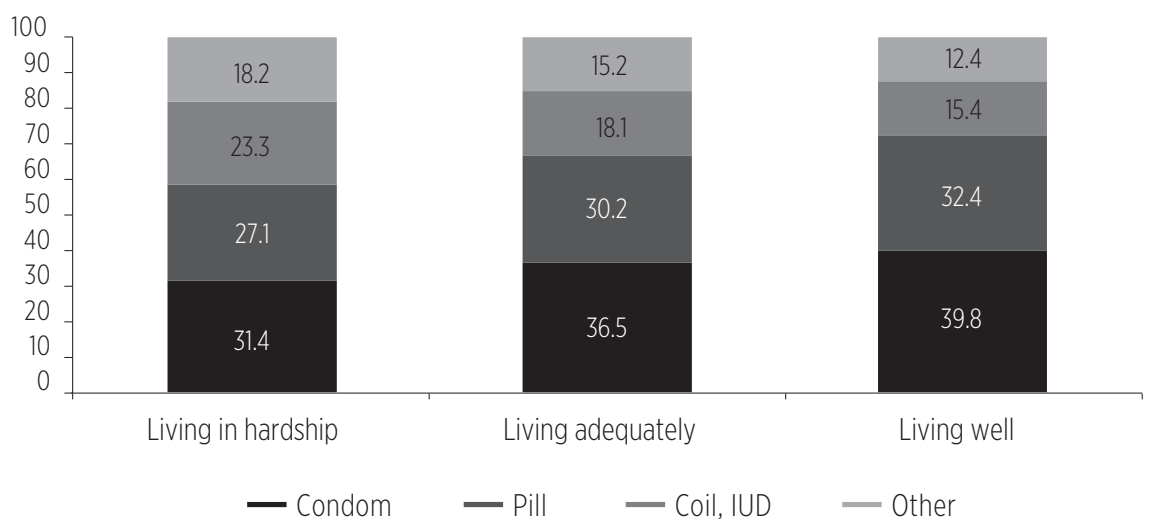

Source: Hungarian Generations and Gender Survey, Wave 3, 2008-2009 (HDRI).

Sample: partnered women aged 20-49 who are not pregnant, not trying to conceive and use birth control. Number of cases: 1608. 


\section{Multivariate analysis of factors affecting the use of the various methods}

To show how mutually dependent socio-demographic factors affect individually the choice of contraceptive method, I compiled a multinomial logit model using the variables employed in the descriptive analysis, joined by the number of children and childbearing intentions for the next three years. Four methods of contraception are compared. The most commonly used one, condoms, acts as the reference category. The model examines what factors influence respondents to use the Pill, the coil or another method instead of condoms.

The results show that the choice between the Pill and condom is affected by age only in the oldest age group: the 45-49s are significantly less likely to be taking hormone pills than their younger counterparts. Presumably there are health reasons for this, as the Pill is less recommended for women as they get older. Surprisingly, there is no similarly significant result for women aged 40-44 in this respect. Partnership status also has an effect on the employed method. The married are less likely to choose the Pill over condom than women living in cohabiting or LAT unions. It may be that those in a more stable, longer-term relationship are better able to cope with the unreliability of condoms than the unmarried. Partnership duration may itself be an explanatory factor, assuming that on average non-marital cohabitations are shorter than marriages. The married may think that they have used hormonal contraception for long enough and would like to switch to a method that burdens their hormonal system less. Women with higher education are even more likely to prefer condoms to the Pill than those with secondary education. With their broader awareness, they may be the most responsive to anti-pharmaceutical campaigns and strive to pay attention to their health in accordance with their knowledge and the expectations of the age.

The choice between coil and condom is also influenced by age group; older women clearly prefer the former method. Unlike condoms, the coil offers permanent protection (or at least a long-term one, lasting over several years), which is particularly recommended for women not planning to have further children. This observation is further supported by the preference of childless and one-child couples for condom over coil. No clear relationship can be seen with education: condoms are preferred over coil by those with the lowest and the highest levels of educational attainment. It can be 
assumed that there are different explanations for this in each case. Coil is fitted in a specialist facility after medical examination. Women in the lowest educational attainment group presumably lack information about this method. Regarding the group with the highest educational attainment, condom may be chosen consciously, and any unpleasantness of using it is offset by the absence of side effects. However, it is surprising to find women in conditions of hardship using coil more often than condom, considering that it requires a sizeable initial expenditure, as does the Pill, even if it is cheaper in the end.

The other, primarily natural methods are used more often than condoms by older age groups and less often by younger ones. The young, as has been seen, do not practice birth control in all cases, and when they do, they mainly use modern methods. Those with the highest educational attainment rely more rarely on natural methods and give preference to condom more frequently than those with secondary education. If children are planned in the near future, however, the use of other methods is more common. This finding is not self-explanatory, as couples planning children prefer natural methods over condoms, not over the hormonal pill, which many people stop using several months before they aspire to conceive a child. A choice between the Pill and condom would have been an easier finding to interpret. In summary, the factors that have the strongest effect on the choice of method are age and educational attainment. These factors influence whether women choose condoms or other methods. Additional examined factors affect the choice at most in individual cases.

Having analyzed the Hungarian data from 2009, let us now return to the question of how the popularity of different methods changed between 1993 and 2009 and whether the fall in the proportion of pill users in Hungary also applies to other countries. 
Table 5: Factors influencing the employed method of contraception (multinomial logit model)

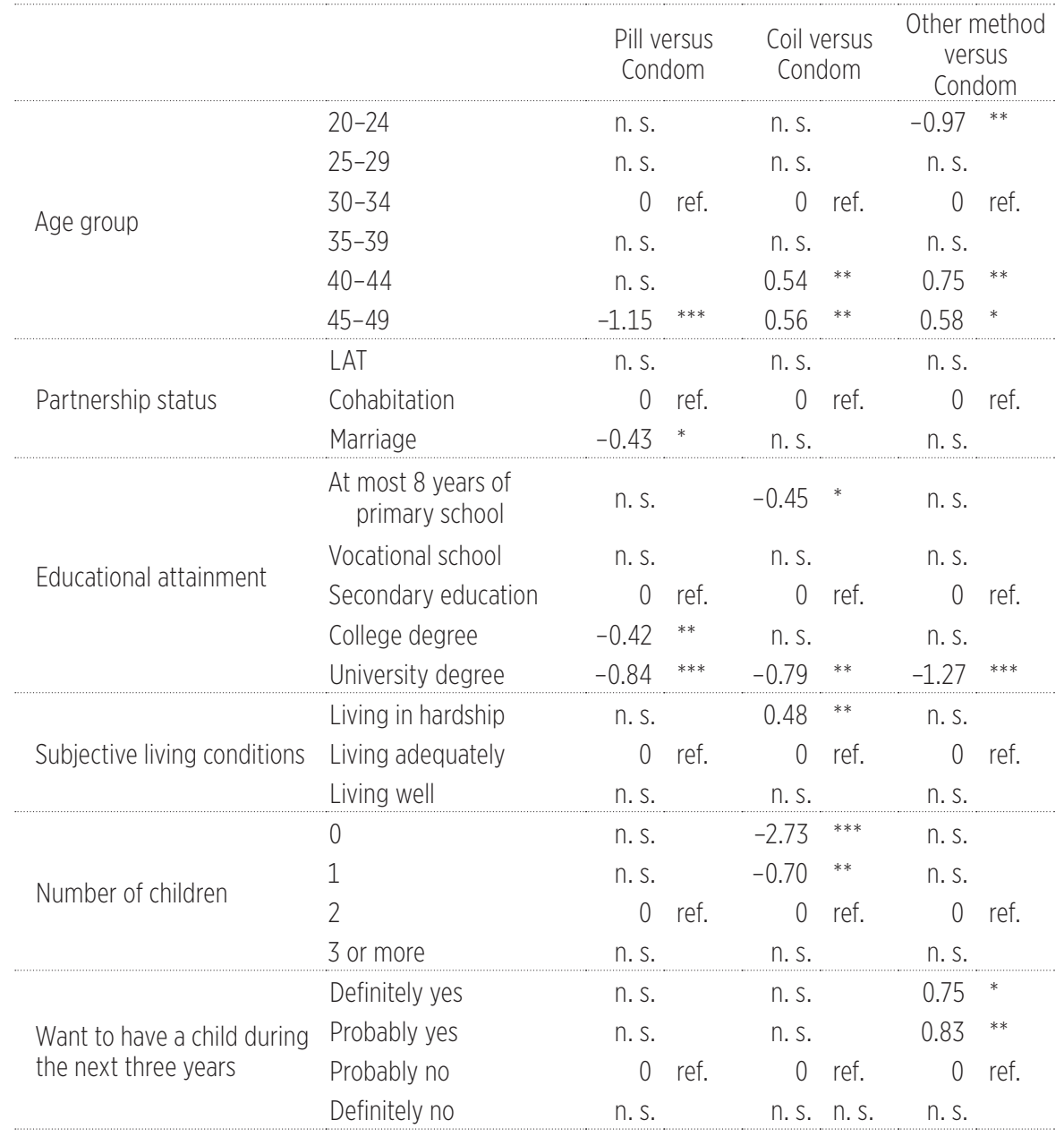

Sources: Hungarian Generations and Gender Survey, Wave 3, 2008-2009 (HDRI).

Sample: partnered women aged 20-49 who are not pregnant and not trying to conceive.

Number of cases: 1608.

Notes: Other control variable: region in which the respondent completed the questionnaire. $\mathrm{n}$. s. = not significant; ref. $=$ reference category. Significance levels: ${ }^{*} p<0.01,{ }^{* *} p<0.05,{ }^{* * *} p<0.001$. 


\section{CHANGES IN THE USE OF METHODS BETWEEN 1993 AND 2009}

Substantial changes had taken place between 1993 and 2009 in the use of different contraceptive methods. Over one decade and a half, the proportion of pill users fell sharply while that of condom users increased (Figure 10). If exactly the same sub-sample is taken, the difference is still more obvious: the proportion of pill users decreased by 18 percentage points among 20-41-year-old partnered women, while that of condom users rose by 25 percentage points. Use of coil declined, but the proportion using traditional methods hardly changed. One can only speculate on what caused this change. The only difference between the wording of the question in the analyzed two surveys was that the 1993 survey inquired about the last four weeks, while the 2009 one made no time restriction, simply asking about present practice. It is not likely that this would cause such a change, but rather a combination of campaigns related to the spread of AIDS in the 1990s and increasing aversion to pharmaceutical interventions in the early $2000 s^{4}$ may have contributed to a preference to condoms over the Pill.

Figure 10: Distribution of contraception methods by partnership status (\%) in 2008-2009 in Hungary

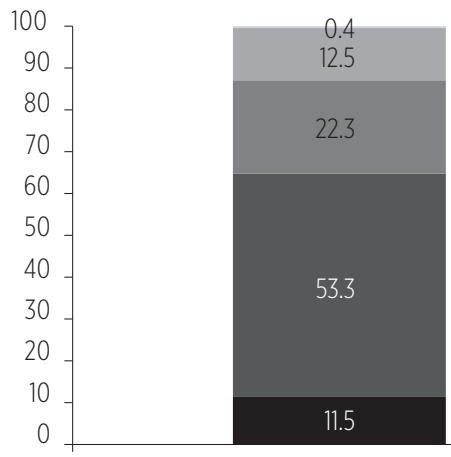

1993

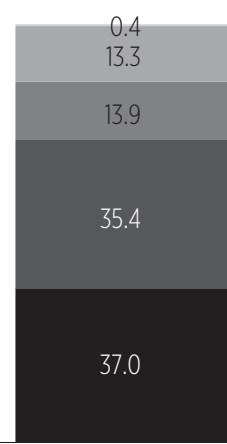

2009

- Condom - Pill - Coil, IUD - Natural method - Other hormonal method

Sources: 1993: UNECE Fertility and Family Surveys, Hungary; 2009: Hungarian Generations and Gender Survey, Wave 3, 2008-2009 (HDRI).

Sample: partnered women aged 20-41 who are not pregnant, not trying to conceive and use birth control. Number of cases: 2073 in 1993; 1207 in 2009.

Notes: Natural methods include interrupted coitus and the calendar method. Other methods are sterilization, local remedies, vaginal pessary, etc.

\footnotetext{
${ }^{4}$ In Hungarian public opinion 40\% of the respondents are openly against medicines was a headline on 18 August 2009, quoting fresh findings by Gfk Hungary (https://www.antsz.hu/data/cms30078/nsz_20090918.pdf).
} 


\section{CHANGES IN EUROPE IN THE 1990S AND 2000 S}

The question here is whether a similar change occurred in other countries that might corroborate, if not explain, the data from Hungary. Results presented here converge with findings from other countries, namely Bulgaria and France (Koytcheva and Philipov, 2008; Bajos et al. 2012).

Indeed comparing the data of the Family and Fertility Survey (FFS) from the 1990s with data of the Generations and Gender Survey (GGS) from the 2000s for Hungary, Bulgaria, Austria, Germany and France shows that the major changes were not confined to Hungary (Table 6). The other countries also show the Pill losing ground since the 1990s, the proportion using it decreased by 20 percentage points, the least in France (by 3.5 percentage points). Yet the three Western countries differ from Hungary in that Pill users are still forming the majority. The fall in Pill usage coincided with a rise in condom use in all countries, 7.2 percentage points in Austria, 5.3 in Germany, 3.3 in France, and 25.4 in Hungary. This became the prime method of birth control in Hungary. Meanwhile the use of the coil and other IUDs increased markedly in the two German-speaking countries, while it decreased in Hungary.

The international comparison also demonstrates that the proportion of women not using contraception hardly changed in Bulgaria and Hungary, but is at a much higher level in Bulgaria (20\%) than in Hungary (under 10\%). (In the other countries it is not possible to draw such a clear conclusion - see the notes to Table 6.)

Bulgaria differs from the other four countries in many ways. First, the proportions of non-users and users of natural methods are high, the latter one (45\%) being the largest group among those using some method of birth control. Secondly, only 10\% use the Pill. The commonest method is condom (30\%) but the proportion of IUD users is also high (18\%), i.e. higher than in Germany or Hungary. Hungary takes an intermediate position here, between the Western countries and Bulgaria. The proportion using a natural method is relatively high, the proportion preferring condom in the 2000s is similar to Bulgaria, but more than a third of women using contraceptives favor the Pill, while in Bulgaria that applies to only one in ten. 
Table 6: Distribution of partnered women aged 20-41 by contraception method, in Hungary and four other European countries in the 1990s and the 2000s (\%)

\begin{tabular}{|c|c|c|c|c|c|c|c|c|c|c|}
\hline \multirow[b]{2}{*}{ Survey } & \multicolumn{2}{|c|}{ AUSTRIA ${ }^{b}$} & \multicolumn{2}{|c|}{ GERMANYb } & \multicolumn{2}{|c|}{ FRANCE } & \multicolumn{2}{|c|}{ BULGARIA } & \multicolumn{2}{|c|}{ HUNGARY } \\
\hline & FFS & GGS & FFS & GGS & FFS & GGS & FFS & GGS & FFS & GGS \\
\hline Year ${ }^{a}$ & 1996 & 2008 & 1992 & 2005 & 1994 & 2005 & 1997 & 2004 & 1993 & 2009 \\
\hline \multicolumn{11}{|c|}{ The use of birth control } \\
\hline Non-users & 19.6 & - & 13.6 & - & 3.7 & $14.2^{c}$ & 18.9 & 22.0 & 5.3 & 8.3 \\
\hline Users & 80.4 & - & 86.4 & - & 96.3 & 85.8 & 81.1 & 78.0 & 94.7 & 91.7 \\
\hline Total & 100.0 & & 100.0 & - & 100.0 & 100.0 & 100.0 & 100.0 & 100.0 & 100.0 \\
\hline Number of cases & 1793 & - & 3273 & - & 1256 & 1178 & 661 & 1610 & 2112 & 1312 \\
\hline \multicolumn{11}{|c|}{ Distribution of methods among women who use contraception } \\
\hline Natural methods & 4.7 & 2.1 & 1.0 & 5.1 & 4.10 & 1.8 & 35.8 & 40.4 & 11.4 & 13.4 \\
\hline Condoms & 14.8 & 22.0 & 4.6 & 9.9 & 7.1 & 10.4 & 27.5 & 28.6 & 11.6 & 37.0 \\
\hline Pill & 66.6 & 39.1 & 83.5 & 56.6 & 63.2 & 59.7 & 16.2 & 9.4 & 52.9 & 35.4 \\
\hline IUD & 10.6 & 22.6 & 6.9 & 12.3 & 21.6 & 22.3 & 17.3 & 17.5 & 22.2 & 13.9 \\
\hline Sterilization & 1.3 & 6.7 & 2.5 & 13.0 & 2.7 & 3.0 & - & 3.4 & 0.9 & \\
\hline Other & 2.0 & 7.5 & 1.5 & 3.1 & 1.3 & 2.8 & 3.2 & 0.7 & 1.0 & 0.3 \\
\hline Total & 100.0 & 100.0 & 100.0 & 100.0 & 100.0 & 100.0 & 100.0 & 100.0 & 100.0 & 100.0 \\
\hline Number of cases & 1442 & 947 & 2829 & 625 & 1209 & 1011 & 536 & 1256 & 2001 & 1207 \\
\hline
\end{tabular}

Sample: partnered women aged 20-41 who are not pregnant, not trying to conceive... and unaware of any medical problem that would impede conception

Notes: a The year in which most interviews occur (in several cases interviews spread over two years).

${ }^{b}$ The harmonized database in Austria and Germany does not contain data on how many use no method, although the questionnaire included a question on this.

Presumably those using no method appear among the missing data, which would account for the low number of cases for the two countries.

c The French data did not distinguish between respondents who wanted a child in the future and those who did not. This is why the proportion of non-users is high

\section{CONCLUSIONS}

The present study has dealt with an issue on which only incomplete information have been available. The aim was to provide a detailed picture of the birth control practices of Hungarian women and the factors that affect them in 2009. A requisite birth control method is of prime importance for avoiding unwanted births and abortions. The latter have tended to decline in the previous ten years, but it still stood at almost 36 abortions for every 100 live births in 2014.

The analyzed data show that about $12 \%$ of partnered women of reproductive age and not planning to have a child still use no birth control and 13\% rely on low- 
efficiency traditional methods. The two groups together amount to a quarter of Hungarian women who are still at risk for unwanted pregnancy. The analysis sheds light on the demographic and social factors that increase the likelihood of not using contraception: higher age, non-marital cohabiting relationship, very low educational attainment, low standard of living, childlessness, and possible plans for having children in the near future (but not at the time of the survey). Women with such characteristics are more exposed than the average to unwanted pregnancy.

It is more difficult to apply these factors to explaining the choice of contraceptive methods, although clear relationships apply here as well: more women with the highest educational attainment choose condoms over any other method of birth control. In higher age groups, the use of the Pill clearly declines in favor of other methods. The use of the coil is more common among women with a secondary education who are childless and of higher age. A lower standard of living also makes the use of the coil more likely, compared to condoms.

The use of natural methods is less frequent among those with higher educational attainment, while it becomes more common at higher ages or if there are plans to have children. It would be worth examining the characteristics of women using natural methods in more detail, as the abortion figures show that over three quarters of woman who undergo abortion used natural methods (KSH, 2012). This study sought a relationship between religious observance and the use of natural methods, on the assumption that Catholics would be using them more frequently, in line with the teachings of their church. No support for this hypothesis, however, could be found.

It would be revealing to devote further research to the role men play in deciding on the method of contraception. Several research articles have shown that men and women often give different responses about the contraception methods employed and that in some cases men might not even know what method their partner is using (Badurashrili et al. 2013). It is important to avoid unwanted pregnancy for both partners and the chances of success are presumably greater if both understand the importance of birth control.

It would also be worth analyzing the degree to which partners control their fertility. Modern contraception methods, in principle, allow unwanted pregnancy to be avoided entirely, but the use of them is presumably not perfect in all cases, and some women do not use them at all. So to what degree are pregnancies conscious planned and to what extent do couples accept unexpected or badly timed pregnancies and babies? Answering these questions is essential to better understand the motivations behind women's birth control decision-making. 


\section{REFERENCES}

Acsádi G., Klinger A. and Szabady E. (1970). Családtervezés Magyarországon. Az 1966. évi Termékenységi és Családtervezési Vizsgálat (TCS) fontosabb adatai [Family planning in Hungary. Main data of the 1966 Fertility and Family Planning Survey]. KSH Népességtudományi Kutatóintézet Közleményei, 27. Budapest: KSH NKI.

Badurashrili, I., Kapanadze, E. and Tsiklaure, S. (2013). Family planning in Georgia. In: Georgian Generations and Gender Survey II Wave National Report. Tbilisi: Georgian Centre of Population Research; United Nations Population Fund, pp.34-49.

Bajos, N., Bohet, A., Le Guen, M. and Moreau, C. (2012). Contraception in France: new context, new practices?, Population and Societies, 492.

Blayo, C. (1991). Les modes de prévention des naissance en Europe de l'Est [Methods of preventing births in Eastern Europe]. Population, 46(3), pp.527-546.

Cahen, F. (2007). From clandestine contraception to the 1967 Neuwirth Act. Why did France drag its feet? Population and Societies, 439, pp.5-8.

Frejka, T. (2008). Birth regulation in Europe: Completing the contraceptive revolution. Demographic Research, 19, pp.73-84.

Klinger A. (1975). Az újabb magyar családtervezési vizsgálatok főbb eredményei II. [Main findings of the more recent Hungarian family-planning surveys II]. Statisztikai Szemle, 3, pp.233-248.

Koytcheva, E. and Philipov, D. (2008). Bulgaria: Ethnic differentials in rapidly declining fertility. Demographic Research, 19(13), pp. 361-402.

KSH (2012). Demográfiai évkönyv 2011 [Demographic Yearbook 2011]. Budapest: Központi Statisztikai Hivatal.

KSH (2015). Demográfiai évkönyv 2014 [Demographic Yearbook 2014]. Budapest: Központi Statisztikai Hivatal.

Monnier, A. (2006). Démographie contemporaine de l'Europe. Evolutions, tendances, défis. [Contemporary demography in Europe. Evolutions, trends, challenges]. Paris: Armand Collin.

Moreau, C. (2011). Contraception. In: Meslé, F., Toulemon, L. and Véron, J., eds., Dictionnaire de démographie et des sciences de la population. [Dictionary of demography and of population sciences]. Paris: Armand Collin, pp.61-64.

Paládi-Kovács, A. (1988-2011). Magyar Néprajz: nyolc kötetben. [Hungarian ethnography: eight volumes]. Budapest: Akadémiai Kiadó.

Quarini, C. A. (2005). History of contraception. Women's Health Medicine, 2(5), pp.28-30.

Surányi S. (1975). A fogamzásgátlás jelenlegi helyzete és lehetőségei Magyarországon [Actual situation and possibilities of contraceptive use in Hungary]. Demográfia, 18(4), pp.521-537.

United Nations Economic Commission for Europe (1999). Fertility and Family Surveys in Countries of the ECE Region. Standard country report: Hungary. Geneva: UNECE.

van de Walle, É. (2005). Birth prevention before the era of modern contraception. Population and Societies, 418, pp.1-4.

Vukovich Gy. (1991). Magyarország népesedéspolitikája [Population policy in Hungary]. Demográfia, 34(1-2), pp.61-70. 